\title{
Classroom Seating for Children With Attention Deficit Hyperactivity Disorder: Therapy Balls Versus Chairs
}

\author{
Denise Lynn Schilling, Kathleen Washington, \\ Felix F. Billingsley, Jean Deitz
}

\author{
KEY WORDS \\ environment \\ participation \\ school-based therapy
}

\begin{abstract}
OBJECTIVE. The purpose of this study was to investigate the effects of therapy balls as seating on in-seat behavior and legible word productivity of students with attention deficit hyperactivity disorder (ADHD). Additionally, social validity was assessed to evaluate teacher and student opinions regarding the intervention.

METHOD. A single subject, A-B-A-B interrupted time series design was employed across 3 students (2 males, 1 female) with ADHD. The study was conducted in a 4th grade inclusive classroom during daily language arts. During phases 1 and 3, the 3 participants and all other class members sat on chairs (inseat on chair); during phases 2 and 4, everyone sat on therapy balls (in-seat on ball). Dependent variables were in-seat behavior and legible word productivity. Data were graphed and visually analyzed for differences between phases.

RESULTS. Results demonstrated increases in in-seat behavior and legible word productivity for the students with ADHD when seated on therapy balls. Social validity findings indicated that generally the teacher and students preferred therapy balls.

CONCLUSION. This study provides evidence that use of therapy balls for students with ADHD may facilitate in-seat behavior and legible word productivity.

Schilling, O. L., Washington, K., Billingsley,F.F., \& Deitz, J. (2003). Classroom seating for children with attention deficit hyperactivity disorder: Therapy balls versus chairs. American Journal of Occupational Therapy, 57, 534-541.
\end{abstract}

Reprinted from The American Journal of Occupational Therapy (Volume 57, Number 5) with permission from The American Occupational Therapy Association, Inc. (AOTA). Copyrighted 2003 by AOTA, 4720 Montgomery Lane, Bethesda, MD 20824.

All rights reserved on products published by AOTA, please call 301-652-2682 or visit www.AOTA.org.

Denise Lynn Schilling, MS, PT, was a graduate student at the time of this study in the Masters of Science Program, Department of Rehabilitation Medicine, University of Washington, Seattle, Washington. Mailing address: 4210 258th Avenue SE, Issaquah, Washington 98029. missdeesg@aol.com

Kathleen Washington, PhD, PT, is Clinical Assistant Professor, Department of Rehabilitation Medicine, University of Washington, Seattle, Washington.

Felix E Billingsley, PhD, is Professor and Chair, Special Education, University of Washington, Seattle, Washington.

Jean Deilz, PhD, OTR/L, FAOTA, is Professor and Graduate Program Coordinator, Department of Rehabilitation Medicine, University of Washington, Seattle, Washington.
Attention deficit hyperactive disorder (ADHD) is the most frequently diagnosed neurobehavioral disorder in childhood (Kauffman, 2001). Current estimates indicate the prevalence of ADHD in the United States ranges from approximately $4 \%$ to $6 \%$ of school-age children (Jaksa, 1998; Rosenblum, 2000) to as high as $13 \%$ in America's inner cities (Goldman, Genel, Bezman, \& Slanetz, 1998; Meaux, 2000). According to Mulligan (2001), children diagnosed with ADHD often experience significant academic and sensory motor problems that make typical school activities a challenge. Goldstein and Goldstein (1992) identified sitting and paying attention as problems for these children in the classroom, and Barkley (1990) noted that children with ADHD often fail to complete assignments or underperform academically.

As a result of the increasing numbers of children with ADHD and the identified problems, Mulligan (2001) made two recommendations. First, she maintained that there is an increased need for therapists to be knowledgeable about ways of managing the classroom behaviors of children with ADHD; second, she identified the need for strategies designed to enhance the school performance of these children. These recommendations seem especially important since many children with ADHD experience a wide range of secondary behavioral and emotional problems at school (Goldstein \& Goldstein, 1992), and more than one third of students with ADHD drop out of school (Rosenblum, 2000). 
Mulligan (2001) suggested that sensory modulation deficits might be a factor in children who demonstrate attention deficits. According to Miller and Lane (2000), sensory modulation "reflects an adjustment in ongoing physiological processes to ensure internal adaptation to new or changing sensory information". (p.3) Furthermore, Hanft, Miller, and Lane (2000) noted that since interactions between tasks, environments, and people continually change, a person's responses may fluctuate considerably, not only day to day, but within an activity. Therefore, it seems that one potential intervention approach to address the behavioral problems of children with ADHD at school is to adapt the environment to meet the children's needs.

Occupational therapy literarure has specifically suggested the implementation of sensory modulation strategies in classrooms for the purpose of improving the classroom performance of children with ADHD (Kimball, 1999; Mulligan, 1996). One possible strategy of using therapy balls for seating was suggested by back-health studies. Incidental to these studies, researchers commented that children using therapy balls in the classroom appeared to improve in attention, sustained sitting, and school performance (Illi, 1994; Witt \& Talbot, 1998). These behaviors are compatible with Ayres' suggestion that an overexcited child may be calmed by gently rocking on a ball (Ayres, 1977). Though these reports and the literature, either directly or indirectly, suggested the use of therapy balls for classroom seating for children with ADHD, prior to the current study, no studies had systematically examined the use of this strategy for such children.

Therefore, the purpose of this study was to examine the use of therapy balls for classroom seating as an intervention for children with ADHD. Two specific research questions were addressed. First, what effect does using therapy balls as chairs have on in-seat behavior? Second, what effect does sitting on balls have on legible word productivity? In addition, social validity was examined to evaluate the teacher's and students' opinions regarding the acceptability and viability of the intervention. Schwartz and Baer (1991) recommended that social validity assessment be a standard part of applied behavioral research since it is possible for an intervention to result in positive changes in dependent variables while simultaneously being identified by research participants as unacceptable.

\section{Method}

This study used a single subject, A-B-A-B interrupted time series design (Kazdin, 1982) across three students with ADHD. During baseline phases (A), participants and all other members of the class used chairs during language arts; during intervention phases (B), participants and all other members of the class sat on therapy balls during language arts. The language arts period was chosen because it occurred at the same time daily (immediately after lunch recess) and it was a time in the children's daily schedules when they were regularly involved in producing written assignments. The total study was 12 weeks in length; each phase was 3 weeks long.

\section{Participants}

A convenience sample was used from a 4th-grade classroom in a public school in the state of Washington. Three children with a diagnosis of ADHD participated in this study; however, all 24 students in the classroom used the balls and chairs. Study procedures were approved by a university human subjects review committee and met the requirements of the school district where the study was implemented.

The participants, 1 female and 2 males, were ages 9 years, 11 months; 9 years, 11 months; and 9 years, 8 months, respectively. Each had a physician's diagnosis of ADHD. In addition, one male had a concomitant diagnosis of oppositional defiant disorder and the other male a concomitant diagnosis of severe behavior disorder. All were of average intelligence or above as defined by a score equal to 80 or above on the Wechsler Intelligence Scale for Children (Wechsler, 1991). Each participant was taking Clonidine, Ritalin, or Adderall. Medications remained constant throughout the study. Prior to the study, all participants regularly demonstrated out-of-seat behavior during the language arts period and required repeated verbal reminders or physical prompts or both from the teacher.

\section{Independent Variable}

The therapy balls selected for classroom use had molded feet (Sit ' $n$ ' Gym ${ }^{\mathrm{TM}}$ by Gymnic) that extended when the ball was not in use to prevent rolling away. Therapy balls were individually fitted for each student in the classroom for a diameter that assured the student could sit comfortably with his or her feet flat on the floor with knees and hips flexed at 90 degrees.

\section{Dependent Variables}

In-Seat Behavior. In-seat behavior (chair) was defined as behavior that occurred when any portion of a participant's buttocks was in contact with the seat portion of the chair (Sugai \& Rowe, 1984) and the four legs of the chair were in contact with the floor. In-seat behavior (ball) was defined as behavior that occurred when any portion of a participant's buttocks was in contact with the ball, the ball was in contact with the floor, and a minimum of one foot of the participant was in contact with the floor. These criteria were measured using momentary real-time sampling (Richards, Taylor, Ramasamy, \& Richards, 1999) whereby following each 10-second interval of the observation the rater scored the participant's behavior as either in-seat or out-of-seat. Since each participant was observed each session for 
five 2 minute periods, this resulted in 60 observations per session per participant. In order to determine percentage of in-seat behavior, the number of observations of inseat behavior was divided by the total number of possible observations that occurred within that session. Therefore, if a session included all 60 observations and if a participant was recorded as being in seat during 20 observations, his or her percentage of in-seat behavior for that session was 33\% (20/60).

Legible Word Productivity. Legible word productivity was defined as the percentage difference between the participant's legible word production and the class mean for legible word production on the same assignment. The percentage difference between the participant's legible word production and the class mean (excluding the study participants) on the same assignment was used because of the high variability in the type and length of writing assignments from one day to the next (e.g., fill in the blank assignments, story writing). Though assignments varied from day to day, all students were given the same assignment on the same day. A method described by Hasbrouck, Tindal, and Parker (1994) was used to assess legibility of produced words. This involved using a window card to expose only one word at a time starting at the end of the document and progressing to the beginning so that words were read out of context.

\section{Procedures}

After consent and assent were obtained and prior to the first baseline session, all students in the class were individually fitted for therapy balls. Each ball was labeled to assure that each student used the ball sized specifically for him or her. An introductory session followed in which the primary investigator answered questions and developed classroom rules, with input from the students, for ball use. Students then had 30 minutes to sit on the balls and independently explore movement and balance. Throughout the study, the teacher was instructed to give no positive or negative feedback on sitting behavior and to intervene only if a student exhibited a behavior deemed by her to be dangerous or destructive. Students were not told the purpose of the study or which members of the class were being observed.

Following the first phase of the study, all students used the balls for 1 week during the language arts period to allow for novelty effects. During this time, no data were collected.

During all baseline and intervention phases, data collection on in-seat behavior (chair and ball) occurred during the middle 40 minutes of the 60-minute language arts session. This allowed for 10 minutes at the beginning of the class for a potential late start and 10 minutes at the conclusion of class for early lesson completion. In order to collect observational data and address reliability, two pediatric therapists were used.
Employing momentary real-time sampling, these two therapists independently and simultaneously observed and scored the in-seat behavior of the same participant. Each therapist wore a wireless headset to hear a preprogrammed tape that announced which participant to record at each 10-second interval. Raters heard the signals and instructions at the exact same moment. Each participant was observed for five 2-minute periods, thus resulting in 60 observations per participant per session. A 30-second break occurred following each 2minute recording period to ease the data collection process for the raters and to allow time for raters to reposition for observation of the next participant in the rotation pattern. The order in which participants were observed each day was randomly selected from a list of six potential patterns (e.g., Pattern \#1: John, Emily, Mike; Pattern \#2: Mike, Emily, John [pseudonyms]). Once a pattern had been selected for a session, it was used five times during that session, and not used again in subsequent sessions until all patterns had been used.

Prior to beginning data collection and periodically throughout the study interrater agreement was examined. The minimum standard was set at 80 percent (Kazdin, 1982).

For out-of-seat-off-of-ball, in-seat-on-ball, and.in-seat asleep behaviors, interrater point-by-point percent agreement (Kazdin, 1982) ranged from $95 \%$ to $100 \%$ (M $=98 \%)$. When a difference in scores between the two raters occurred, the mean score of the two raters was used because it is more reliable than scores of a single rater when the reliability between the two raters is high (Tuckman, 1988). Though data were collected for 12 sessions during each phase, during some phases, some participants had less data points because of classroom absences.

To assess legible word productivity, five writing samples were randomly selected per phase for each participant. The primary investigator evaluated all selected samples for word productivity using the process described under dependent variables. To assess reliability, a second evaluator, blind to the study, evaluated two randomly selected papers per phase per participant. Average interrater agreement (using the formula for percent agreement) was $94 \%$.

The primary investigator checked procedural reliability once weekly with the day randomly selected (Billingsley, "White, \& Munson, 1980). She used a checklist describing the classroom environment (e.g., levels of feedback to the students from the teacher, consistency of staff in the classroom, daily schedule, and absence of discussion regarding potential study outcomes). Procedural reliability was $100 \%$, thus suggesting that the environment and the teacher's management style and expectations remained constant during the study. 
At the completion of phases two, three, and four, during class time, the teacher and all 24 students completed social validity questionnaires. The teacher and student questionnaires had nine and six questions, respectively. Three choices (ball, chair, and no difference) followed each question. Topics covered in the questionnaires included classroom behavior and assignment completion. Sample teacher questions were: "Students had better attention to task when sitting on _-" "Students remained seated longer when sitting on __." "Students were least disruptive to peers when sitting on ." Sample student questions were: "I finish my work better sitting on _.." "I can listen and pay attention better sitting on __." Prior to implemenration, a physical therapist, an occupational therapist, and an educator reviewed the questions for relevance and potential for biasing results.

At the end of the study, the teacher and the students were all given blank sheets of paper and asked to write about their overall perceptions regarding using balls, chairs, or both. Instructions were to "Write a sentence or two on how you felt about sitting on balls. It can be what you liked or didn't like."

\section{Results}

\section{In-Seat Behavior}

Figure 1 indicates that improvements in sitting behavior were evident for all the participants when using therapy balls for seating. John displayed in-class sleeping behavior in addition to his disruptive out-of-seat activities during phases 1 and 3, when seated on a chair. During phases 2 and 4, when seated on the ball, there were no sessions in which John was asleep.

Emily, the participant with no coexisting conditions, displayed consistent patterns of behavior on the chair and on the ball. During chair phases she was in constant motion and often out-of-seat. During therapy ball phases she remained in her seat appearing still and steady.

As noted in Figure 1, Mike presented differently from the other 2 participants. During baseline he was in-seat approximately $75 \%$ of the time, considerably more than the other participants were. However, observations revealed that when Mike was out of his seat, he spent his time talking with classmates, removing items from other students' desks, and frequently interrupting the teacher. When seated quietly in his chair he would often read a pleasure book and not participate in class activities. Mike frequently left the class and would not return for prolonged periods and often left school early. As a result, Mike was not present for the ball introduction and the five-session novelty phase. After the first week of intervention, which served as Mike's novelty phase, his in-seat behavior on the ball was consistently above his behavior on the chair.

\section{Legible Word Productivity}

It was hypothesized that if students with ADHD increased their in-seat behavior when sitting on balls versus chairs, the amount of written work they produced would also increase. As noted in Figure 2, productivity percentage difference from the class mean for five randomly selected assignments per phase indicated that all 3 participants' legible word productivity was generally higher when seated on therapy balls. Note that when a participant was present in class but completed no written work, that participant received a score of zero.

\section{Social Validity}

All 3 participants with ADHD reported preferring balls to chairs for comfort, writing, and productivity. In addition, 21 other students in the class reported via questionnaire that they believed the therapy balls were more comfortable, improved their writing, and increased their ability to listen and finish class work. Of this group, 17 students reported that they preferred balls, 2 preferred chairs, and 2 had no preference.

At the conclusion of the study, all students also were given an opportunity to put in writing their opinions of sitting on balls in the classroom. Students could write more than one comment. Of the 30 responses made by the students, 26 were positive in support of sitting on balls and 4 were negative. The 4 negative responses were reports of back discomfort with 2 of the 4 disliking the lack of a backrest. Additionally, John reported, "a downside of balls is being unable to sleep in class." Of the 26 positive responses in support of sitting on balls, 13 reported increased back comfort or improved posture, 6 reported increased freedom of movement, 4 reported increased attention, and 3 reported improved handwriting. A sampling of the positive written comments regarding sitting on balls were: "You can keep your brain active even when you're bored" (typical child-TC), "My posture improves" (Mike), "1 can get my work done better" (Emily), "Writing is funner than ever" (TC).

The teacher's responses also supported the use of balls for classroom seating. Sample teacher comments included "Although students are bouncing, they are more focused on what I am saying," "The noise level immediately decreases," "Following the use of the balls the students seem to remain calmer and focus better for about 30 to 45 minutes," and "For some students work production has dramatically improved." At the completion of this study the teacher continued to use therapy balls for seating for the children with ADHD and ordered additional balls for other students, thus further supporting the social validity of this intervention. 


\section{Discussion}

Findings of this study support the use of therapy balls for students with ADHD as an alternative classroom seating option. For all participants, both in-seat behavior and legible word productivity improved when seated on the therapy balls. This study demonstrated that the intervention was effective with 3 students with ADHD who varied in terms of gender, concomitant diagnoses, and medications. This provides some support for the generality of the findings and is important since ADHD often coexists with other disorders (Barkley, 1990; Mulligan, 2001; Silver, 1990). In addition, the teacher's and students' general preferences for therapy balls for seating supported the social validity of the intervention.

Therapists and the teacher reported observing substantial student differences in movement patterns (e.g., bouncing, gently rocking) while seated on the therapy balls. One explanation could be self-modulation of personal sensory needs by each student in order to maintain an optimal state of arousal (Dunn, 2000; Kimball, 1999; Mulligan, 2001; Williams \& Shellenberger, 1994). An example of an individual student's variation in movement pattern was observed in Mike who, at the beginning of a session, gently rocked on the therapy ball and vigorously bounced toward the conclusion of the same session. This variation in movement patterns may reflect responses to changing sensory needs, possibly explained by the theory that a person's sensory needs continually change as they are affected by interactions with tasks, environments, and people (Brown, Tollefson, Dunn, Cromwell, \& Filion, 2001; Cohn, Miller, \& TickleDegnen, 2000; Dunn, 1997; Dunn \& Brown, 1997; Mulligan, 2001)

For Emily, the use of the ball immediately addressed safety issues. On the chair she was in constant movement, often out-of-seat and, when seated, she generally assumed extreme postures that were potentially dangerous (e.g., tipping her chair and balancing on the top of the backrest). By contrast, on the ball, she needed to keep at least one foot in contact with the floor in order to maintain sitting balance, thus minimizing classroom disruption and safety concerns.

For John, therapy balls for seating decreased in-class sleeping behavior. It appeared that when John attempted to sleep, slight movement of the ball would alert him and he would immediately sit up. This was further supported by John's comment regarding his inability to sleep when seated on the therapy ball.
According to Mulligan (2001), a common function of the school-based therapist is collaborating with teachers to develop strategies to improve behavior and classroom performance of students with ADHD. She further identified the need to evaluate the effectiveness of such strategies. The current study addressed this need and exemplified the use and evaluation of a strategy involving collaboration with a teacher for both implementation and success.

\section{Limitations}

Limitations of the study included the short duration of the study (12 weeks), the sample size, the use of a single classroom, and the fact that quality of written work was not assessed. Although the teacher reported improvements in class work for the participants when seated on the balls versus chairs, no formal assessments were performed on the written assignments regarding spelling, sentence structure, or content.

\section{Directions for Future Research}

Therapists in school system practice need to continue to Study the use of therapy balls in the classroom for the purpose of helping students succeed. Three directions for future research are warranted. First, the longitudinal effects of using therapy balls for classroom seating for children with ADHD should be studied. Second, the use of therapy balls for children with other diagnoses (e.g., autism, Down syndrome) merits investigation. Last, future research should include dependent variables such as classroom noise levels, classroom behaviors, (e.g., raising hand, verbal outbursts), peer relationships, quality of word production, and student performance in a variety of academic areas.

\section{Conclusion}

This study suggests that the use of therapy balls for classroom seating is one strategy that therapists in school system practice might consider when working with children with ADHD who are having difficulty meeting school expectations of staying on task and remaining seated. Additionally, this intervention strategy was found to be compatible with inclusive educational practice and interdisciplinary teaming. 


\section{Acknowledgments}

This research was funded in part by a grant from the U.S. Department of Health and Human Services, Maternal and Child Health Bureau 1:0 the University of Washington, Center for Leadership in Pediatric Physical Therapy Education. We would like 1:0 thank the students and families who made this research possible and the teachers, administrators, and coworkers who provided resources and assistance.

\section{References}

Ayres, A. J. (1977). Sensory integration and learning disorders. Los Angeles: Western Psychological Services.

Barkley, R. (1990). Attention deficit hyperactivity disorder: A handbook for diagnosis and treatment. New York: Guilford.

Billingsley, F., White, 0., \& Munson, R. (1980). Procedural reliability: A rationale and an example. Behavioral Assessment, 2, 229-24l.

Brown, C., Tollefson, N., Dunn,W., Cromwell, R., \& Filion, D. (2001). The Adult Sensory Profile: Measuring patterns of sensory processing. American Journal of Occupational Therapy, 55, 7582.

Cohn, E., Miller, L., \& Tickle-Degnen, L. (2000). Parental hopes for therapy outcomes: Children with sensory modulation disorders. American Journal of Occupational Therapy. 54, 36-43.

Dunn, W (1997). The impact of sensory processing abilities on the daily lives of young children and their families: A conceptual model. Infants and Young Children, 9, 23-35.

Dunn, W (2000). Habit: What's the brain got to do with it? Occupational Therapy Journal of Research, 20, 6s-20s.

Dunn, w., \& Brown, C. (1997). Factor analysis on the Sensory Profile from a national sample of children with our disabilities. American Journal of Occupational Therapy. 51, 490-495.

Goldman, L., Gene!, M., Bezman, R., \& Slanetz, P. (1998). Diagnosis and treatment of attention deficit/hyperactivity disorder in children and adolescents. JAMA, 279(14), 1100-1107.

Goldstein, S., \& Goldstein, M. (1992). Hyperactivity-Why won't my child pay attention? New York: Wiley.

Hanft, B., Miller, L., \& Lane, S. (2000, September). Toward a consensus in terminology in sensory integration theory and practice: Part 3: Observable behaviors: Sensory integration dysfunction. Sensory Integration Special Interest Section Quarter/y. 23, 1-4.

Hasbrouck, J., Tindal, G., \& Parker, R. (1994, Winter). Objective procedures for scoring student's writing. Teaching Exceptional Children, 18-22.
Illi, U. (1994). Balls instead of chairs in the classroom? Swiss Journal of Physical Education, 6, 37-39.

Jaksa, P. (1998). Fact sheet on attention deficit hyperactivity disorder. Retrieved October 18, 2002, from www.add.org/content/abc/factsheet.htm

Kauffinan, J. (2001). Characteristics of emotional and behavioral disorders of children and youth (7th ed.). Columbus: Merrill Prentice Hall.

Kazdin, A. E. (1982). Single-case research design. New York: Oxford University Press.

Kimball, J. (1999). Sensory integration frame of reference: postulates regarding change and application to practice. In P. Kramer \& J. Hinojosa (Eds.), Frames of Reference for Pediatric Occupational Therapy (2nd ed., pp. 169-204). Philadelphia: Lippincott Williams \& Wilkins.

Meaux, J. (2000). Stop, look, and listen: The challenge for children with ADHD. Issues in Comprehensive Pediatric Nursing, 23, 1-13.

Milkr, L., \& Lane, S. (2000, March). Toward a consensus in terminology in sensory integration theory and practice: Part 1: Taxonomy of neurophysiological processes. Sensory Integration Special Interest Section Quarter/y, 23, 1-4.

Mulligan, S. (1996). An analysis of score patterns of children with attention disorders on the Sensory Integration and Praxis Tests. American Journal of Occupational Therapy, 50, 647-654.

Mulligan, S. (2001). Classroom strategies used by teachers of students with attention deficit hyperactivity disorder. Physical \& Occupational Therapy in Pediatrics, 20, 25-44.

Richards, S., Taylor, R., Ramasamy, R., \& Richards, R. (1999). Single subject research: Applications in educational and clinical settings. San Diego: Singular.

Rosenblum, G. (2000). Your child and ADHD. Singapore: Creative Publishing International.

Schwanz, I., \& Baer, D. (1991). Social validity assessments: Is current practice state of the art? Journal of Applied Behavior Analysis,24, 189-204.

Silver, L. (1990). Attention deficit hyperactivity disorder: Is it a learning disability or a related disorder? Journal of Learning Disabilities, 23, 394-397.

Sugai, G., \& Rowe, P. (1984, February). The effect of self-recording on out-of-seat behavior of an EMR student. Education and Training of the Mentally Retarded, 23-28.

Tuckman, B. (1988). Conducting educational research (3rd ed.). San Diego: Harcoutt Brace Jovanovich.

Wechsler, D. (1991). Manual.for Wechsler Intelligence Scale for Children-3rd edition. San Antonio, TX: The Psychological Corporation.

Williams, M., \& Shellenberger, S. (1994). How does your engine run? Albuquerque, NM: Therapy Works.

Witt, D., \&Talbot, R. (1998, February). Let's get out kids on the ball Advance for Physical Therapists, 27-28. 


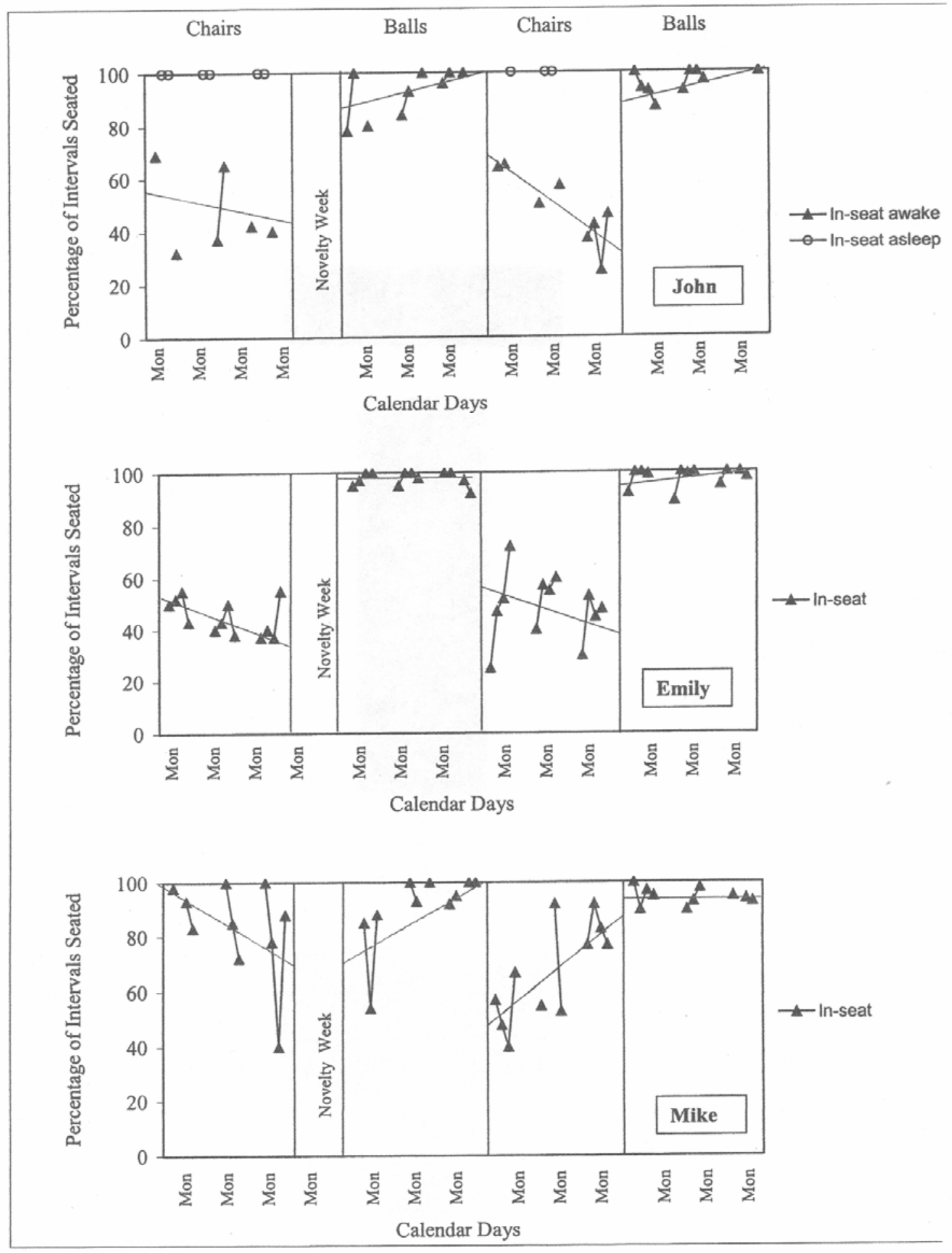

Figure 1. In-seat behavior by session. (Connected data points represent consecutive days within the same week. Variability in the number of data points was the result of a non-school day or student absence from class.) 


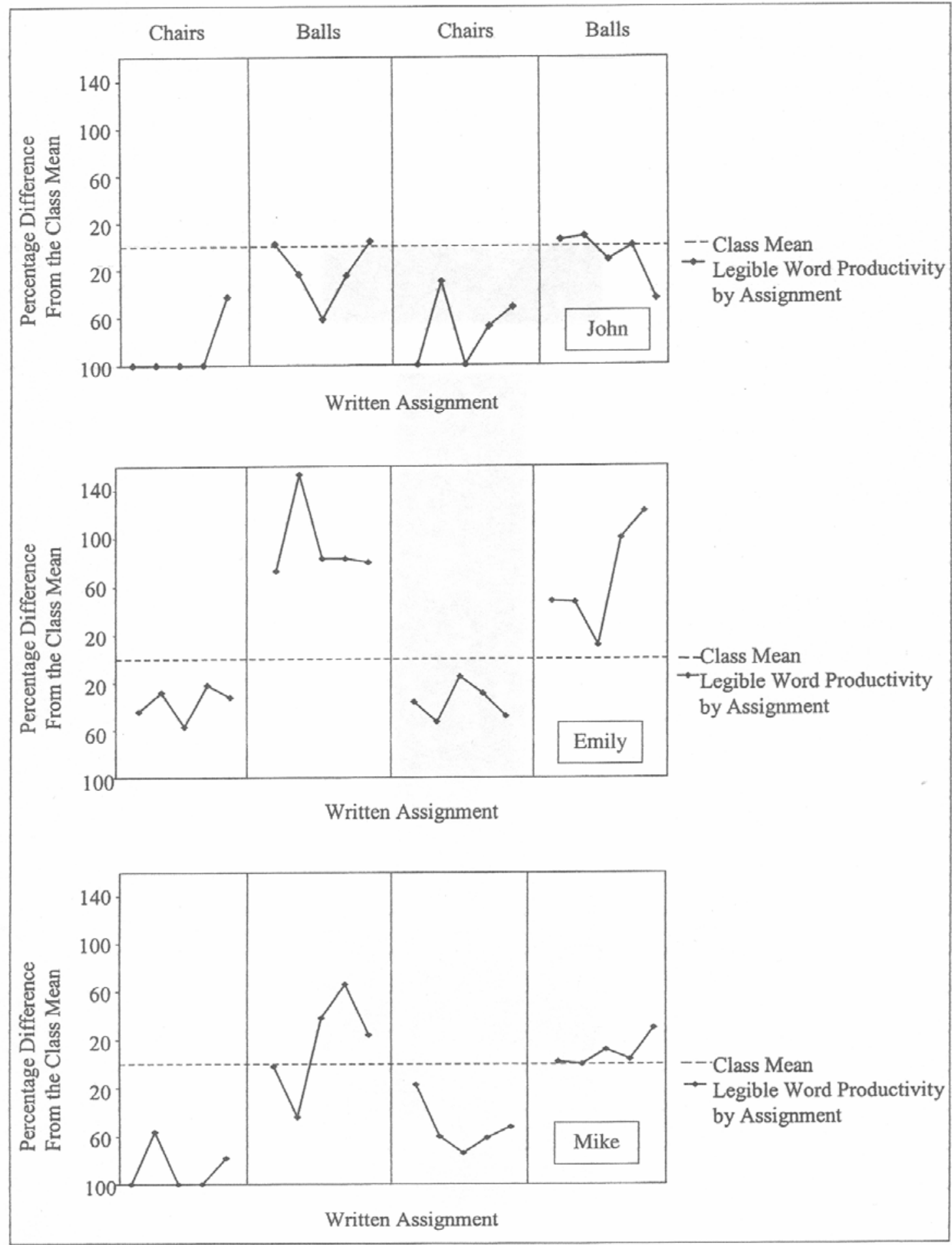

Figure 2. Comparison of legible word productivity to the class mean. (Each participant's productivity on each paper was based on the percentage difference between his or her production and that of the class mean on the same assignment. 